\title{
UM PERCURSO PARA A EMOÇÃO: SOBRE A OBRA TRAJETÓRIA DAS PAIXÕES - UMA RETÓRICA DA ALMA
}

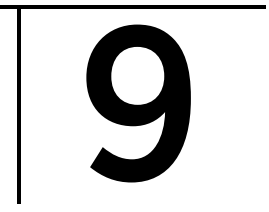

\section{AN EMOTIONAL ROUTE: PATHWAYS OF PASSION - A RHETORIC OF THE SOUL}

\author{
RADI, Alan Ribeiro \\ RADI, Alan Ribeiro \\ Doutorando em Linguística pela Universidade de Franca. \\ Trabalho desenvolvido com fomento da Coordenação de Aperfeiçoamento de Pessoal de Nível \\ Superior - Brasil (CAPES) - código de financiamento 001. \\ Membro do Grupo PARE (Pesquisa em Argumentação e Retórica)), certificado pelo CNPq. \\ E-mail: alanradi@hotmail.com. \\ ORCID ID: https://orcid.org/0000-0002-0794-8174
}

\section{FIGUEIREDO, Maria Flávia}

Doutora em Linguística e Língua Portuguesa pela Unesp.

Docente permanente do Programa de Pós-Graduação em Linguística da Universidade de Franca.

Líder do Grupo PARE (Pesquisa em Argumentação e Retórica), certificado pelo CNPq.

E-mail: mariaflaviafigueiredo@yahoo.com.br.

ORCID ID: https://orcid.org/0000-0002-7047-4020

\section{RESUMO}

O legado teórico construído sobre o pathos, desde Aristóteles até a atualidade, tornou-se objeto de interesse para as pesquisas do Grupo PARE (Pesquisa em Argumentação e Retórica) nos últimos anos. Como fruto de suas elucubrações, a líder do grupo propôs um novo modo de analisar as emoções: por intermédio de um percurso denominado "trajetória das paixões". Embasado em tal proposição, o grupo produziu um acervo de reflexões e análises dos mais diversos textos/discursos para testar a eficácia teórica dos recentes estudos. Os frutos de tais análises, sua importância para os estudos da contemporaneidade e novas possibilidades de pesquisa nessa seara é o que buscamos evidenciar nesta resenha da obra intitulada Trajetória das paixões: uma retórica da alma.

Palavras-chave: Pathos. Trajetória das paixões. Grupo PARE. 


\section{ABSTRACT}

The theoretical legacy built on pathos, from Aristotle to the present day, has become the object of interest for Grupo PARE's research in recent years. As a result of such considerations, a new way of analyzing emotions, i.e., through a route that is called "the pathway of passions" was proposed by PARE's leader. Based on this proposition, the PARE group (Research in Argumentation and Rhetoric) produced a collection of reflections and analyzes of the most diverse texts/speeches to test the theoretical effectiveness of their recent studies. The fruits of such analyzes, their importance for contemporary studies, and new research possibilities in this field constitute what we seek to highlight in this review of the book Trajetória das paixões: uma retórica da alma.

Keywords: Pathos. Pathway of passions. Grupo PARE.

\section{INTRODUÇÃO}

Esta resenha dedica-se a refletir sobre a obra intitulada Trajetória das paixões: uma retórica da alma, não de maneira convencional, mas com um olhar próprio do pesquisador. As especificidades desse olhar estão relacionadas ao abandono de um gesto de interpretação passivo e de mera absorção apenas do conteúdo apresentado. Essa passividade sede lugar a um leitura curiosa e indagadora de novas possibilidades de contribuição com o tema proposto. Esse gesto, além de ser próprio do pesquisador, é poeticamente contributivo e responsável pelo incessante funcionamento maquinário científico. Passemos, então, às considerações sobre o contexto de produção da obra.

\section{CONTEXTO DE PRODUÇÃO DA OBRA}

A necessidade de comunicação capacitou o homem com a mais encantadora das habilidades, o domínio sobre as linguagens. Dessa maneira, é bastante reconhecida a afirmação de que a linguagem é vital para a constituição da sociedade, pois, apenas por meio dela, o homem se organiza para dissolver os problemas inerentes à convivência social. Tais problemas fogem à lógica e se instauram no campo da plausibilidade. $\mathrm{O}$ plausível pode e, de fato, causa distanciamento entre os espíritos. Assim, a retórica, de acordo com Meyer (2000, p. XLII), "é antes de tudo um ajuste de distância entre os indivíduos".

A retórica se fundamenta sobre três pilares: o discurso (logos), a imagem que o orador engendra de si (ethos) e a disposição de espírito 
do auditório (pathos). Para esta resenha, importa-nos o funcionamento da retórica pelo viés do pathos, embora seja imprescindível reconhecer a indissociabilidade dessas três instâncias que apresentamos.

Em sua obra Retórica, Aristóteles mostrará que

a persuasão pode ser obtida através dos ouvintes quando o discurso afeta suas emoções; com efeito, os julgamentos que emitimos variam segundo experimentamos sentimentos de angústia ou júbilo, amizade ou hostilidade. Todos os esforços dos atuais autores de retórica, nós o afirmamos, são dirigidos no sentido de produzir esses efeitos. (ARISTÓTELES, 2011, p. 45-46)

O excerto que citamos da obra do estagirita evidencia a forma com que as emoções que causam dor ou prazer alteram nosso julgamento a respeito dos fatos, daí seu forte caráter persuasivo. Além disso, mostra como a preocupação concernente às emoções norteava os tratados a respeito de retórica já em sua época, em torno de quatro séculos antes de cristo. A persuasão de caráter passional é tão profícua e instigante que as indagações a respeito do pathos atravessaram todos esses séculos e, ainda hoje, nos debruçamos sobre esse assunto na ânsia de responder as lacunas do entendimento acerca dessa instância.

A busca pelo entendimento cada vez mais consolidado das emoções levou Maria Flávia Figueiredo, em parceria com Luana Ferraz e Acir de Matos Gomes, a organizar um livro intitulado Trajetória das paixões: uma retórica da alma. Os organizadores são membros do grupo PARE (Pesquisa em Argumentação e Retórica), cadastrado no CNPq e sediado na Universidade de Franca, desde 2013. Além de membro, Figueiredo é líder do grupo e docente permanente do Programa de Pósgraduação em Linguística na mesma instituição.

O livro supramencionado foi publicado em 2020 pela editora Unifran e pode ser encontrado em versão digital ${ }^{1}$ e impressa. A obra é composta por 22 capítulos escritos por membros do grupo PARE - em vários níveis de formação: doutorado, mestrado e iniciação científica - e, também, por pesquisadores convidados de outras instituições brasileiras. Além disso, conta com "Prefácio" escrito por Eduardo Lopes Piris, "Apresentação" redigida por Valmir Ferreira dos Santos Júnior e "Quarta capa" elaborada por Luiz Antônio Ferreira. Os diferentes capítulos concernem a uma temática comum, a trajetória das paixões. Essa teoria

1A versão digital pode ser encontrada para download no seguinte endereço eletrônico: $<$ http://mariaflaviafigueiredo. com.br/downloads/paixoes.pdf>. 
é uma formulação de Figueiredo que propõe a análise das paixões sob a perspectiva de uma trajetória. Disporemos maiores detalhes sobre esse tema ao tratar especificamente do capítulo escrito pela autora.

A obra representa, a nosso ver, um potencial de abrangência, alargamento e novas possibilidades da teoria recém formulada. Dizemos isso porque o gesto de experimentação da proposição de Figueiredo, sob as mais diversas configurações de textos e discursos, configura um inventário de novas reflexões demandadas pela própria teoria.

Salientamos que o que nos levou a escrever esta resenha foi a consciência do posicionamento ativo e dialógico que a ação de ler/ interpretar nos imputa. Mediante uma teoria nova, como é o caso do mote do objeto de nossa resenha, podemos encontrar nos capítulos, por mais que não seja a intenção do autor fazê-las emergir, outras possibilidades de pesquisa e possíveis respostas para novas questões levantadas que se escondem nas entrelinhas das reflexões propostas. $\mathrm{O}$ evidenciar de novas possibilidades é o que desejamos apresentar neste trabalho.

Assim, no próximo item, apresentaremos uma breve explanação acerca de cada um dos capítulos e destacaremos pontos que nos pareçam passíveis de novas questões acerca do tema. Isso o faremos, é claro, sem deixar de apontar para o leitor as evidências qualitativas que tornam imprescindíveis a leitura da obra.

\section{DO CONTEÚDO DA OBRA}

O primeiro capítulo do livro, formulado pela professora Maria Flávia Figueiredo, recebe o título de "Ampliação e aplicabilidade analítica da 'trajetória das paixões'". Esse texto teórico constitui o cerne da obra e dita o tom das reflexões analíticas subsequentes, devido ao caráter inovador das reflexões que o constituem. A inovação advém do fato de as paixões e sua análise serem propostas de forma a percorrer uma trajetória até seu acontecimento efetivo. A trajetória das paixões concretiza-se em cinco etapas: disponibilidade, identificação, despertar da paixão, mudança de julgamento e ação. Descrevamos, de acordo com as proposições da autora, cada uma dessas etapas.

A disponibilidade é referente à pré-disposição afetiva que determinado auditório tem em relação a sofrer ou não uma paixão específica. Figueiredo (2020) lança mão de um recurso metafórico para explicar o funcionamento dessa etapa: a figura das prateleiras em uma despensa. Partamos do pressuposto de que alguns itens são posicionados mais à frente em uma prateleira pela frequência com que são usados, e 
outros são deixados mais atrás pelo mesmo motivo. Uma organização bastante semelhante se dá em nossa mente em relação às paixões. Os fatores determinantes para essa "disponibilidade" são, na esteira de raciocínio da autora, nossas crenças, valores, hábitos e experiências acumuladas. Esse esquema de funcionamento faz com que o conjunto das paixões mais e menos disponíveis seja extremamente variável em cada auditório. Daí, a tão conhecida proposição em relação à necessidade de um orador conhecer intimamente seus alocutários. Um equívoco em relação ao contexto passional do auditório pode ocasionar, por parte do orador, a construção de um discurso equivocado, que levaria o auditório a sofrer paixões diferentes daquelas pretendidas por ele, e o resultado persuasivo se tornaria catastrófico.

A partir do momento em que uma paixão se encontra disponível em um auditório e o orador consegue saber de qual se trata, este passa a ter subsídios para a construção de um discurso capaz de despertar, em seu auditório, processos de identidade. Assim, tem-se origem a segunda etapa do processo, chamada de identificação. O desdobramento dessa etapa se dá em primeira pessoa, dito de outra forma, há uma identificação do indivíduo, membro do auditório, em relação à enunciação do orador, ele se percebe nela e por intermédio dela. $\mathrm{O}$ discurso revela para ele quem ele é, quais são seus valores, crenças, virtudes, temores e objetos de sua felicidade, ainda que isso não pareça claro nem para ele mesmo. A autora afirma que, quando o orador alcança tal empreendimento mediante seu auditório, este se sente interpelado na alma e torna-se aberto para a próxima etapa da trajetória rumo à paixão.

Mobilizado por uma paixão disponível em seu âmago e sentindose identificado com os valores que nortearam o discurso proferido, o auditório passa a sentir os sintomas físicos da emoção que o toma. Estamos, assim, mediante a etapa denominada despertar da paixão. Nesse instante, os "sintomas" da paixão ecoam na matéria física daqueles que foram tomados por ela. Tais sensações não estão no domínio do imaginário, mas são empiricamente sentidas. Assim, sustenta-se a afirmação de que as emoções provocam dor e/ou prazer. A dor e o prazer sentidos fazem com que o homem reavalie seu posicionamento sobre determinado tópico. Inicia-se, dessa forma, a próxima etapa do percurso delineado por Figueiredo (2020).

A mudança de julgamento sofre impacto direto das sensações de dor e ou prazer derivadas da etapa anteriormente descrita. Consoante a pesquisadora, a mudança de julgamento põe em evidência uma espécie 
de conjunção entre o corpo e a alma. A alteração do estado físico, seja positiva, seja negativa, encaminha o intelecto para uma revisão e possível modificação de seu veredito acerca do assunto objeto do discurso. Em razão dessa alteração, o auditório é impelido a agir. Chegamos, assim, à última etapa do processo de despertar das emoções: a ação.

O movimento de agir do auditório, seja qual for a válvula motriz que o motivou, é fruto do sucesso logrado nas etapas anteriores da trajetória. Referendando Meyer (2000), podemos afirmar que, se houve ação, a paixão também se fez presente. A ação encerra o ciclo proposto na trajetória porque constitui o objetivo de qualquer discurso retórico. O orador que leva o auditório a agir desempenhou, de maneira satisfatória, as funções técnicas e intelectivas próprias dessa figura tão importante para o acontecimento retórico.

Urge salientar que, sobre as três últimas etapas, já encontramos estudos na literatura, embora elas não sejam propostas nesse formato. As duas etapas iniciais, contudo, são inovadoras nos estudos das emoções e contribuem sobremaneira para o entendimento do despertar das paixões. A primeira delas, por exemplo, tem caráter pré-discursivo, que é um assunto pouco abordado sob o arcabouço teórico da Retórica.

Os estudos que enfatizam o caráter passional das interações comunicacionais vêm à tona em um momento em que a humanidade parece aceitar e ter, ao mesmo tempo, sérios problemas com o seu lado emocional, aflorado pelo desconhecimento e não aceitação dessa faceta constitutiva do ser. Essas reflexões não nos parecem uma coincidência, e sim uma necessidade analítica dos discursos veiculados na/pela contemporaneidade. A esse respeito, Figueiredo (2020, p. 54) escreve: "com Aristóteles fui conduzida a repensar minha natureza. Passei, então, a conceber o ser humano como aquele que, ao longo de toda sua existência, luta para ter controle racional daquilo que Ihe escapa e, ao mesmo tempo, o constitui: seu universo passional". Levando em consideração a obra que culminou em decorrência dessas reflexões, torna-se redundante afirmar quão cara é a trajetória das paixões para os estudos contemporâneos acerca das emoções.

Depois de apresentar o capítulo teórico e norteador dos demais trabalhos, disporemos nossas considerações sobre as reflexões oriundas desse aparato metodológico.

Em "Imagens e figuras de construção na trajetória das paixões: aspectos cognitivos e funcionalidade retórica", Antônio Suárez Abreu busca evidenciar de que maneira os processos cognitivos, relacionados 
à criação de narrativas, produzem ou melhoram os efeitos retóricos de nossos discursos/textos sob a perspectiva da trajetória das paixões. Sob nossa ótica, dois aspectos evidenciam a importância teórica desse capítulo. Em primeiro lugar, pelo fato de o pesquisador lançar mão do conceito de presença advindo do Tratado da argumentação. Entretanto, o autor não só o evoca, mas, também, o ilustra sob a perspectiva dos processos cognitivos, pois, ao tratar da presença, os autores do tratado não são claros sobre como se dá seu acontecimento. Nesse caso, por intermédio do arcabouço teórico cognitivista, evidencia-se uma possibilidade prática da manifestação dessa estratégia argumentativa, a presença. Em segunda instância, consideramos importante o fato de o autor haver dado ênfase, em suas análises, a textos impressos, isto é, a materialidade textual manifestada graficamente, uma vez que essa modalidade de acesso aos discursos é bastante recorrente na atualidade. Esse fato coloca o capítulo em profunda consonância com a obra, que busca perscrutar as emoções sob o viés da trajetória e sua ocorrência em práticas discursivas da atualidade.

Em "Storytelling: a força da narrativa cognitiva na trajetória das paixões", Giovanni Aurélio de Britto, também embasado por estudos cognitivistas, faz associações entre os conceitos de narrativa cognitiva e storytelling com as etapas da trajetória das paixões. Nesse processo, o autor busca evidenciar a forma com que as narrativas desempenham um papel profícuo como estratégias de alto valor persuasivo. A grande contribuição dessas reflexões, a nosso ver, está ligada ao fato de o autor comprovar o quão persuasivo uma prática pode ser, nesse caso, a de contar histórias, tendo como suporte de análise as etapas que constituem o acontecimento das paixões.

Em "A impermanência das emoções: Sócrates e a trajetória das paixões", a professora Letícia Machel Lovo aplica o percurso das paixões em uma análise da importante obra da filosofia Apologia de Sócrates. O que torna esse capítulo interessante é o viés que a autora seleciona para conduzir suas análises, a busca pela boa vida. Esse tópico, que foi norteador de várias reflexões filosóficas do mundo grego, assume importante valor para o auditório. Conduzidas por essa temática, as análises da pesquisadora apontam cada uma das etapas da trajetória das paixões no construto discursivo, por meio do qual o personagem Sócrates buscou apaixonar seu auditório.

Em "A trajetória das paixões na parábola do filho pródigo", Luiz Alves de Souza contribui com as reflexões de Figueiredo ao colocar 
em prova uma vez mais a nova teoria proposta. Ao elencar as possíveis paixões, o autor evidencia as incursões que as etapas da trajetória exercem sobre o acontecimento das paixões. A procedência bíblica do objeto de estudo selecionado - parábola - contribui, sobremaneira, com a manifestação prática do construto teórico nas mais diversas esferas comunicativas.

Em "De olho em Aquino: como a percepção provoca paixões", Pedro Luiz Rodarte Gulke expõe uma reflexão sobre os sentidos internos da faculdade sensitiva, estudo oriundo das reflexões de Tomás de Aquino, e o despertar das paixões. Nessa correlação, evidencia os pontos em que esses sentidos podem participar da constituição das etapas da trajetória proposta por Figueiredo. As proposições levantadas tornam-se caras para as reflexões norteadoras da obra pelo fato de se vincularem, ainda que não explicitamente, à afirmação de Meyer de que a paixão é sempre resposta àquilo que o outro causa em mim, já que, segundo o legado tomista, as paixões acontecem como resposta à realidade que nos cerca.

Em "Fé passional: a trajetória das paixões no mito da criação", Luan Marques Domingues e Valmir Ferreira dos Santos Junior contribuem com as reflexões acerca da trajetória das paixões ao verificar como tais etapas se fazem presentes no despertar das emoções no texto bíblico. Ao evidenciar cada uma das etapas, bem como as possíveis paixões delas decorrentes, evidencia-se, também, o potencial retórico das paixões mediante um assunto de bastante interesse por parte da humanidade - o mito criacional - que é munido de baixa ou nenhuma evidência científica.

Em "O mover das paixões na sentença judicial", Acir de Matos Gomes, Gabriel Campos Frade Machado e Lívia Furlan Telini objetivam analisar uma decisão judicial para entender se as etapas da trajetória das paixões, consequentemente algumas emoções, podem ser constatadas em uma sentença judicial. A rica contribuição dessas reflexões repousa sobre a presença das paixões, evidenciadas pela trajetória, na sentença judicial, discurso marcadamente conhecido por seu suposto caráter imparcial e objetivo. Esse fato coloca em cena a natureza passional do ser humano que pode ser captada por intermédio do uso que ele faz das múltiplas linguagens.

Em "Rasgar-se e remendar-se: a via crucis das paixões em vidas secas", Daniela Rodrigues de Oliveira busca descrever as possíveis paixões despertadas pelo romance Vidas secas (Graciliano Ramos) em seu auditório. As paixões são analisadas sob a perspectiva da trajetória 
das paixões. A autora, dessa forma, contribui com as reflexões acerca da trajetória ao demonstrar sua aplicabilidade no gênero literário narrativo romance. As análises empreendidas consideram as paixões despertadas com base na crítica social empregada pelo romancista em sua obra tematizada pela seca da região árida do Brasil.

Em "O pathos e os degenerados: Rita Von Hunty e o despertar da paixão do amor", Ticiano Jardim Pimenta tece uma reflexão a respeito da etapa da disponibilidade como espaço interdiscursivo para o processo do despertar das paixões. Assim, mostra como o sexismo e os esteriótipos oriundos dele atuam para gerar, nos adeptos dos valores binários de sexualidade, disponibilidade pathetica para a paixão do ódio em relação aos pertencentes à comunidade LGBTQIA+, que o autor denominará de "os degenerados". Além das instigantes considerações acerca da etapa da disponibilidade e sua profícua execução nas práticas discursivas, o autor ressalta, mesmo que de maneira não explicitada, o mecanismo retórico das paixões proposto por Michel Meyer, qual seja, a forma com que as paixões devolvem o equilíbrio nas representações de um em relação ao outro. Dessa maneira, o autor esclarece que, se a disponibilidade do auditório é para o ódio, o sucesso argumentativo do discurso analisado decorre do equilíbrio despertado pela paixão do amor.

Em "Análise do filme 'Coringa' sob a perspectiva da trajetória das paixões", Sirlene Aparecida Pessalacia Barretto apresenta uma aplicação teórica da trajetória das paixões em uma cena do filme "O coringa". Nesse capítulo, percebe-se um ponto bastante interessante: a seleção que a autora faz do auditório em que possivelmente se despertarão algumas emoções. Esse não será composto pelos espectadores do filme, e sim por um de seus personagens: o Coringa. Ainda que seja de maneira não premeditada pela autora, essa seleção nos leva a perceber que as paixões são tão intrínsecas ao ser humano que, até mesmo os arquétipos humanos podem ser uma fonte de análise para as paixões.

Em "Trajetória das paixões: uma aplicação pedagógica", Ana Lúcia Magalhães demonstrou a eficácia teórica da trajetória das paixões ao evidenciar a manifestação de suas etapas no fazer pedagógico voltado para alunos de ensino superior. Tais constatações se evidenciaram quando a autora analisou o comportamento de professores de uma das unidades da Fatec, Faculdade Tecnológica do Estado de São Paulo. Ademais, o capítulo contribui com reflexões acerca da instância do pathos na busca por ressaltar a não polarização negativa ou positiva das paixões, e sim a neutralidade da força exercida por essa instância seja para o bem, seja para o mal. 
Em "Uma escolha de Sofia: a trajetória das paixões no discurso de médicos da linha de frente da covid-19", Ananias Agostinho da Silva e Maria Flávia Figueiredo elaboram análises que nos permitem identificar como diferentes paixões podem ser despertadas nos diversos auditórios mediante o discurso de médicos que atuam na linha de frente da Covid-19. A trajetória das paixões norteia as reflexões analíticas e demonstra-se eficaz para o entendimento das emoções mediante as situações mais precárias, que nos levam a fazer escolhas difíceis, tais como as obrigatoriamente efetuadas pelos médicos diante da falta de leitos nos hospitais durante as crises mais acentuadas da pandemia.

Em "As paixões dos vulneráveis: análise retórico-passional de relatos de pessoas em situação de rua", Gabriel Henrique Haddad busca evidenciar a contribuição dos estudos da paixão, bem como de sua trajetória, para o entendimento de um amplo problema social, a situação de rua. O auditório selecionado como alvo das emoções é o das pessoas em situação de rua que foram entrevistadas pelo pesquisador. A seleção do auditório, assim como do tema da pesquisa, evidencia a força do acontecimento das paixões. Elas são tão fortes que levam as pessoas a praticar as mais distintas ações, no caso desse estudo, nocivas. Outro caráter interessante do estudo é a aplicação inversa da trajetória das paixões. O pesquisador partiu da etapa da ação já efetivada, os entrevistados já se encontram em situação de rua. A partir disso, o estudo buscou entender, por intermédio das outras etapas da trajetória, quais paixões ocasionaram mudança de julgamento que desencadeou essa ação. A nosso ver, esse estudo possui grande relevância porque demonstra ser possível o pesquisador partir de uma situação já concretizada e investigar qual o provável processo passional responsável pelo fato.

Em "A força do pathos e sua trajetória na campanha 'Call'", Mariana Ferreira Santos e Acir de Matos Gomes buscam revelar as etapas da trajetória das emoções em um texto multimodal e logram êxito nesse propósito. Para isso, lançam mão de uma análise, via trajetória das paixões, da campanha "Call" do instituto Maria da Penha. Essa campanha foi produzida em função do aumento de casos de violência doméstica ocasionado pelo isolamento social preventivo ao coronavírus. A carga emocional da situação retratada pelo objeto de análise é grande e fortemente avassaladora para o auditório. Dessa maneira, o desvelamento das etapas da trajetória em um texto multimodal contribui para o entendimento de que, independentemente do gênero e da constituição do discurso, a trajetória se faz presente no acontecimento das emoções. 
Em "No amor não existe medo: a trajetória das paixões no discurso do Papa João Paulo II", Ana Cláudia Ferreira da Silveira e Maria Sílvia Rodrigues-Alves analisam um excerto do discurso proferido pelo pontífice em uma Jornada Mundial da Juventude. Com o auxílio da trajetória das paixões, as autoras tentam identificar as correlações existentes entre as emoções do amor e da confiança para o apaziguamento do medo. $\mathrm{O}$ trabalho traz duas grandes contribuições para a nova teoria. A primeira está relacionada à possibilidade de pensar em paixões que atuam como suporte para o acontecimento de outra paixão. A segunda contribuição importante se dá pelo fato de análise extrapolar os elementos linguísticos e buscar evidências passionais, também, em elementos paralinguísticos.

Em "O humor no púlpito e o despertar da confiança", Luana Ferraz estabelece um diálogo entre o humor e a paixão da confiança via trajetória das paixões. A pesquisadora apresenta a análise de um discurso proferido por Padre Léo na comunidade televisiva católica Canção Nova. Esse capítulo apresenta algumas contribuições importantes para os estudos retóricos. A primeira delas é a demonstração de alguns elementos que contribuem para o despertar da confiança no auditório: o uso de exemplos com ethos forte e aceito, o uso de narrativas de cunho verossímil e a adoção de uma linguagem prosaica, comum ao auditório. Ademais, as reflexões evidenciam a presença do humor no discurso religioso. Esse fator importa porque, por muito tempo, a convivência entre humor e fé parecia inconcebível se consideramos a crença de demonização do riso. $\mathrm{O}$ uso do humor, em contexto religioso, mostra como as estratégias retóricas estão a serviço das necessidades modernas de comunicação. A partir do século XX, o pudor relacionado ao risível perdeu sua força e, além disso, a igreja - não só esse orador e nem só o catolicismo - passou a utilizar o humor como estratégia argumentativa para deixar mais leve a transmissão da fé e seu código de conduta.

Em "Em busca de uma essência mais verdadeira: a trajetória das paixões na canção 'perfume do invisível'", Farnei Santos busca ressaltar as etapas da trajetória na música mencionada no título, interpretada pela cantora Céu. O discurso analisado, ou seja, a letra da música, é munido de profundo potencial retórico, que se manifesta, por intermédio de conotações, em um número sucinto de versos. Nas análises via trajetória das paixões, o pesquisador mostra como o conteúdo semântico da letra encaminha o auditório para um convite ao desnudar de sua essência mais pura. Para tal, fica patente a importância da etapa da disponibilidade para a paixão da confiança. Nesse tocante, encontramos uma reflexão 
de grande valia para os futuros estudos acerca da trajetória, qual seja: a hipótese de que a paixão da confiança é a base de todo processo que objetiva convencer um auditório.

Em "How music makes us feel 'alive': a pathways of passion analysis", Valmir Ferreira dos Santos Junior empreende uma análise da música Alive (Sia) sob o viés da trajetória das paixões. A grande contribuição desse capítulo se assenta no fato de as análises não evidenciarem apenas aspectos da letra da música, senão de toda composição melódica da canção. O pesquisador demonstra de que maneira o construto musical, teoricamente analisado, contribui para o despertar das emoções pretendidas pelo orador.

Em "É proibido proibir: a paixão do ódio como estratégia retórica", Delzio Marques Soares apresenta uma análise do fonograma em que Caetano Veloso defende sua canção intitulada "É proibido proibir", no festival de música de 1968. Por intermédio das etapas da trajetória das paixões, o pesquisador revela como o ódio fomentou a produção do discurso de Caetano mediante seu auditório. A busca por mudanças sociais e culturais constituem o pano de fundo para a produção do objeto de pesquisa. Além de evidenciar a maneira com que o orador do discurso analisado alcançou seus objetivos por intermédio da emoção, podemos alargar a possibilidade de reflexão que esse texto nos apresenta. Embora os objetivos do autor do capítulo não tenham caminhado para essa direção, tais reflexões nos permitem levantar um possível questionamento: o contexto ditatorial, de fato, tem o poder de apagar a retórica nos discursos? Principalmente nos discursos de cunho passional?

Em “'Acreditar é o que nos move': paixões do amor e da confiança como elementos de persuasão em um filme publicitário", Priscila Antunes de Souza aponta as etapas da trajetória das paixões em um curta-metragem publicitário da empresa LG. No objeto de análise, a frase "acreditar é o que nos move" é inserida em um contexto imagético de inclusão de pessoas com diversidade funcional. Como ressaltado pela pesquisadora, a veiculação desse conteúdo coloca em evidência a preocupação da marca com a questão de inclusão. Esse capítulo traz uma importante contribuição para os estudos retóricos por trazer à baila uma questão bastante sensível e que, por muito tempo, foi ignorada pela sociedade, a inclusão. Ademais, contribui porque atesta a presença das etapas da trajetória de maneira completa na peça publicitária analisada: no tema, nas imagens (cores e formas geométricas) e na música (partitura). Assim, 
mostra-nos como os discursos multimodais lançam mão de estratégias retóricas que exorbitam a linguagem verbal para atingir o propósito comunicativo da persuasão.

Em "Auditório particular, disponibilidade e identificação: aproximações entre processos retórico-identitários", Alan Ribeiro Radi busca entender as aproximações existentes entre as duas etapas iniciais da trajetória das paixões e a instância do auditório particular. Para isso, lança mão do conceito de ideologia proposto pela AD e acredita que esse mecanismo participa na constituição da base identitária comum a esses elementos retóricos. Ademais, analisa um discurso proferido pelo Pastor Silas Malafaia com o intuito de ilustrar as reflexões teóricas elaboradas por ele. O andamento do trabalho dá margem para o aparecimento de outras questões para futuras pesquisas. Apresentamos, a título de exemplo, uma possível subdivisão da etapa da disponibilidade em pré e pós-discursiva, embora esse não tenha sido o enfoque dado pelo autor.

\section{PARA FINALIZAR SEM ENCERRAR}

Uma proposta teórica sempre configura um presente para o universo acadêmico, significa acréscimo instrumental para auxiliar no entendimento dos campos do saber. Esse é o caso da teoria norteadora da obra que, aqui, resenhamos. O livro não apresenta uma teoria apenas, senão a teoria colocada à prova por um grupo de pesquisa sério e consolidado. Dessa maneira, tecemos alguns comentários com a finalidade de encerrar nossas considerações neste espaço discursivo.

A respeito do caráter contributivo da obra, Luiz Antonio Ferreira, ao produzir a quarta capa, salienta: "o livro, sem dúvida, presta contribuição expressiva aos estudos retóricos de nossos dias, pois, como a própria paixão humana, cria um laço de identidade com o outro que, por sorte, somos nós, os leitores".

Não podemos ignorar as influências que a obra anteriormente publicada pelo grupo PARE - Retórica e multimodalidade (2018) exerceu sobre a recente publicação que resenhamos. Os estudos em textos de caráter multimodal tornaram-se marca registrada do grupo. Essa insígnia fica patente na seleção dos corpora analisados nos diversos capítulos. A esse respeito, o prefaciador da obra comenta:

[...] o conjunto de textos desta obra coletiva revela também a atualidade e a produtividade dos estudos retóricos na contemporaneidade ao levar em conta a presença do fazer retórico nos mais distintos campos da atividade humana, 
tais como o jurídico, religioso, literário, médico, filosófico, publicitário, fílmico, digital, entre outros. (PIRIS, 2020, p. 13)

Escolhemos, para finalizar, um excerto de Meyer que representa o espírito do grupo PARE. Ele verbaliza:

Sócrates sabe que não sabe nada. Não pretende responder às perguntas que faz: sabe que essas perguntas permanecem, como sabe que quem acha tê-las resolvido é um impostor, que ele o desmascarou como tal e que é inútil ocupar uma posição de notável em nome de um pretenso conhecimento de soluções, o qual não se possui efetivamente. (MEYER, 2000, p. XVIII).

Nessa ordem de pensamento, registramos um convite, em nome de todos os autores dessa obra, para que a leiam e venham estudar e aprofundar essas questões conosco. As perguntas não desaparecerão, entretanto, poderão ser iluminadas por nossas respostas provisórias.

\section{REFERÊNCIAS}

ARISTÓTELES. Retórica. Tradução de Edson Bini. São Paulo: Edipro, 2011.

FERREIRA, Luiz Antonio. Quarta capa. In: FIGUEIREDO, Maria Flávia; GOMES, Acir de Matos; FERRAZ, Luana (orgs.). Trajetória das paixões: uma retórica da alma. Franca: Unifran, 2020.

FIGUEIREDO, Maria Flávia. Ampliação e aplicabilidade analítica da "trajetória das paixões". In: FIGUEIREDO, Maria Flávia; GOMES, Acir de Matos; FERRAZ, Luana (orgs.). Trajetória das paixões: uma retórica da alma. Franca: Unifran, 2020. p. 29-55.

FIGUEIREDO, Maria Flávia; GOMES, Acir de Matos; FERRAZ, Luana (orgs.). Trajetória das paixões: uma retórica da alma. Franca: Unifran, 2020.

MEYER, Michel. Prefácio. In: ARISTÓTELES. Retórica das paixões. Introdução, notas e tradução do grego de Isis Borges B. da Fonseca. São Paulo: Martins Fontes, 2000. p. XVII-LI

PIRIS, Eduardo Lopes. Prefácio. In: FIGUEIREDO, Maria Flávia; GOMES, Acir de Matos; FERRAZ, Luana (orgs.). Trajetória das paixões: uma retórica da alma. Franca: Unifran, 2020. p. 11-13.

RECEBIDO EM: 27/05/2021

ACEITE EM: 07/06/2021 